\title{
Substituição do farelo de soja pela mistura raspa de mandioca e uréia em dietas para vacas mestiças em lactação ${ }^{1}$
}

\author{
Ricardo Pimentel Ramalho2, Marcelo de Andrade Ferreira ${ }^{3,5}$, Antonia Sherlânea Chaves \\ Véras $^{3}$, Djalma Cordeiro dos Santos ${ }^{4}$, Carmem Valéria de Araújo Cavalcanti ${ }^{6}$, Vitória Régia \\ Ramos de Albuquerque Rocha ${ }^{6}$
}

\author{
${ }^{1}$ Parte da tese de Doutorado do primeiro autor - PDIZ - UFPB/UFRPE/ UFC. Trabalho realizado por intermédio do acordo IPA/UFRPE. \\ 2 CCBS/FEJAL - CESMAC \\ ${ }^{3}$ Departamento de Zootecnia/UFRPE. \\ 4 IPA. \\ ${ }^{5}$ Bolsista de Produtividade em Pesquisa do CNPq. \\ ${ }^{6}$ Mestre em Zootecnia - PPGZ - UFRPE.
}

RESUMO - Com o objetivo de avaliar os efeitos da substituição do farelo de soja pela mistura raspa de mandioca+uréia sobre o desempenho, o consumo e a digestibilidade dos nutrientes em dietas à base de palma forrageira (Opuntia ficus indica, Mill) e silagem de sorgo, oito vacas mestiças Holandês:Gir (60 30 dias em lactação e $491 \mathrm{~kg}$ de PV inicial) foram distribuídas em dois quadrados latinos $(4 \times 4)$. A mistura raspa de mandioca+uréia substituiu $0,33,67$ e $100 \%$ do farelo de soja nas dietas. Os consumos de matéria seca (expressos em $\mathrm{kg} / \mathrm{dia}$, \% do PV, g/ $\mathrm{kg}^{0,75}$ do PV), MO, PB, EE, FDN e CHOT diminuíram linearmente com a inclusão da raspa de mandioca. As ingestões de FDN (\%PV), FDA, CNF e NDT não foram afetadas pelos níveis de raspa de mandioca+uréia nas dietas. A inclusão de raspa de mandioca+uréia influenciou a digestibilidade aparente de todos os nutrientes, sendo descrita por função quadrática. A produção de leite, a produção de leite corrigida para $4,0 \%$ de gordura e a produção de gordura diminuíram linearmente em 30, 20 e 0,8 g/dia, respectivamente, enquanto o teor de gordura e a eficiência alimentar, em $\mathrm{kg}$ de leite corrigido para 4,0\% de gordura $/ \mathrm{kg}$ de $\mathrm{MS}$, não foram influenciadas pelos níveis de substituição do farelo de soja na dieta.

Palavras-chave: consumo, digestibilidade, eficiência alimentar, nitrogênio não-protéico, produção de leite

\section{Replacement of soybean meal with urea plus cassava scrapings in diets for crossbred lactating cows}

\begin{abstract}
This trial was conducted to investigate the replacement of soybean meal with a mixture of urea plus cassava scrapings on nutrient intake, digestibility, and production of crossbred lactating cows fed diets containing forage cactus (Opuntia ficus indica, Mill), sorghum silage, and concentrate. Eight crossbred holstein:zebu cows averaging $60 \pm 30$ days in milk and initial body weight (BW) of $491 \mathrm{~kg}$ were randomly assigned to two replicated $4 \times 4$ Latin squares and were fed diets with increasing levels of urea plus cassava scrapings: $0,33,67$ or $100 \%$. Replacing soybean meal with urea plus cassava scrapings linearly decreased the intakes of $\mathrm{DM}\left(\mathrm{kg}, \% \mathrm{BW}\right.$ and $\left.\mathrm{g} / \mathrm{BW} \mathrm{kg}^{0.75}\right), \mathrm{OM}, \mathrm{CP}, \mathrm{EE}, \mathrm{NDF}$, and TC However, the increasing dietary levels of urea plus cassava sacrapings did not affetc the intakes of NDF (\% BW), ADF, NFC, and TDN. Apparent digestibilities of all nutrients showed significant quadratic effects with increasing urea plus cassava scrapings. Milk yield, milk yield corrected for $4.0 \%$ fat and milk fat yield all decreased linearly by 30,20 and, $0.8 \mathrm{~g} /$ day, respectively, while fat content and feed efficiency, expressed as $\mathrm{kg}$ of $4.0 \%$ fat corrected milk/kg of DM, were not changed by decreasing soybean meal in the diet.
\end{abstract}

Key Words: digestibility, intake, milk yield, non-protein-nitrogen (NNP), protein

\section{Introdução}

O farelo de soja constitui importante fonte protéica em dietas para vacas em lactação. Contudo, recentes flutuações da moeda americana têm refletido em constantes aumentos no seu custo, tornando praticamente inviável sua inclusão nas dietas.
Como características comuns a todos os ruminantes, as vacas leiteiras possuem elevada capacidade de digestão dos carboidratos, eficiente utilização da proteína dietética e habilidade em utilizar nitrogênio não-protéico (NNP) por meio da atividade microbiana ruminal. As bactérias ruminais são especialmente ativas nos processos de síntese protéica e podem utilizar como substratos para essa síntese, além 
dos aminoácidos, fontes de NNP como precursores para formar novos aminoácidos. Essas reações permitem que o animal economize compostos nitrogenados e obtenha proteína a partir de fontes de NNP, como a uréia, a qual pode ser utilizada como fonte suplementar na dieta desses animais.

Assim, a proteína ingerida pelo ruminante pode passar para o abomaso sem sofrer ação dos microrganismos (denominada proteína não degradada no rúmen - PNDR) ou ser degradada no rúmen (PDR), com hidrólise das ligações peptídicas (proteólise) e liberação dos peptídeos e aminoácidos, utilizados pelos microrganismos ruminais para a síntese de proteína microbiana (PM). Esses aminoácidos podem ainda ser deaminados, com liberação de amônia e ácidos graxos voláteis (AGV's). Ainda no rúmen, a amônia é convertida em compostos nitrogenados e, quando em excesso, é absorvida pela parede ruminal e transportada ao fígado, via circulação sanguínea, onde é transformada em uréia. Essa uréia pode ser reciclada ou eliminada via urina ou leite (NRC, 1985; Santos et al., 2001).

A quantidade de proteína no intestino delgado para a absorção é a soma da proteína que compõe os microrganismos (PM) e da proteína alimentar que escapa da digestão ruminal ilesa (PNDR), além daquela contida nas secreções endógenas (mucoproteína da saliva e enzimas provenientes do abomaso) e nas células de descamação - células epiteliais provenientes do trato respiratório e/ou do efeito abrasivo do alimento com os tecidos da boca, do esôfago, do retículorúmen, do omaso e do abomaso (NRC, 1985; NRC, 2001).

A uréia é uma fonte de NNP largamente utilizada na alimentação de ruminantes, todavia, quando a quantidade de carboidratos é insuficiente para o aproveitamento do NNP para a síntese microbiana, ocorre deficiência ou ineficiência na utilização da proteína dietética, com redução da digestão dos carboidratos e perda de nitrogênio na forma de amônia (Fregadolli et al., 2001). Outra desvantagem da utilização de uréia é a diminuição na ingestão de alimentos, ocasionada pela baixa palatabilidade (Church, 1974), ressaltando-se que o consumo é considerado mais importante que a digestibilidade para explicar as variações no desempenho dos animais (Mertens, 1994) e que níveis elevados de NNP podem intoxicar o animal pelo excesso de liberação de amônia, elevando o pH ruminal com a diminuição do crescimento da população microbiana, e reduzindo, ainda mais, o consumo (NRC, 1985; Roseler et al., 1993).

$\mathrm{O}$ processo fermentativo de aminoácidos com o aproveitamento da amônia para a síntese de PMé parcialmente controlado pela disponibilidade de carboidratos no rúmen
(Russell et al., 1981), pois a produção de adenosina trifosfato (ATP) está correlacionada à síntese de PM, favorecendo a utilização de aminoácidos absorvidos para a formação de mais PM. Van Soest (1994) afirma que a escassez de carboidratos promove maior fermentação dos aminoácidos da dieta, com aproveitamento da cadeia carbônica para a produção de energia na forma de ATP e liberação da amônia. Uma conseqüência imediata do aumento da concentração de amônia no rúmen é o decréscimo da retenção de nitrogênio pelo animal, visto que há limite na reciclagem do nitrogênio absorvido pelas paredes ruminal e intestinal, sendo o excesso eliminado na urina ou no leite, em forma de uréia (NRC, 1985).

A otimização da produção de proteína microbiana depende do sincronismo entre as disponibilidades de amônia e de cadeia carbônica para o crescimento microbiano. Essa sincronia, por sua vez, depende do tipo de carboidrato e da fonte de NNP oferecidos na dieta.

Lines \& Weiss (1996) testaram diferentes fontes de proteína para vacas holandesas em lactação e não encontraram diferenças significativas no consumo e na digestibilidade dos nutrientes ou no desempenho dos animais quando da utilização de farelo de soja, uréia, proteína de origem animal ou feno de alfafa tratado com amônia.

Oliveira et al. (2001) avaliaram a substituição do farelo de soja $(0 ; 22,8 ; 45,6$ e $68,4 \%$, com base na MS $)$ pela mistura milho+uréia em dietas para vacas holandesas lactantes (450 kg de PV e produção diária de $20 \mathrm{~kg}$ de leite) e verificaram reduções tanto do consumo de MS como da produção de leite, sem nenhuma alteração nas digestibilidades dos nutrientes da dieta.

Comportamento semelhante foi registrado por Silva et al. (2001), ao substituírem o farelo de soja pela mistura milho moído+uréia nas mesmas proporções, com base na MS, em dietas para vacas mestiças Holandês:Gir, lactantes, com peso vivo médio de $511,8 \mathrm{~kg}$ e produção média diária de $18,75 \mathrm{~kg}$ de leite.

Melo et al. (2003b) também observaram redução nos consumos dos nutrientes e nas produções de leite com a substituição parcial do farelo de soja $(0 ; 18 ; 36$ e $54 \%$ com base na MS) pela mistura palma forrageira+uréia em dietas para vacas holandesas lactantes com produção média diária de $20 \mathrm{~kg}$ de leite e $600 \mathrm{~kg}$ de PV.

Este estudo foi realizado com o objetivo de avaliar os efeitos da substituição do farelo de soja pela mistura raspa de mandioca+uréia sobre o desempenho, o consumo e a digestibilidade dos nutrientes em vacas mestiças em lactação. 


\section{Material e Métodos}

O experimento foi realizado na Estação Experimental de Arcoverde, pertencente à Empresa Pernambucana de Pesquisa Agropecuária (IPA), localizada no município de Arcoverde, Agreste de Pernambuco.

Foram utilizadas oito vacas mestiças 5/8 Holandês:Gir, multíparas, aos $60 \pm 30$ dias de lactação, com peso vivo médio inicial de $491 \mathrm{~kg}$ e produção média inicial de $13,2 \mathrm{~kg}$ de leite por dia.

O experimento teve duração de 68 dias, divididos em quatro períodos de 17 dias, dez para adaptação dos animais às dietas e sete para coleta.

Os animais foram distribuídos, de acordo com a ordem de lactação, em dois quadrados latinos $(4 \times 4)$ e alojados em estábulo com cocho individual para controle do consumo de alimentos. $\mathrm{O}$ fornecimento das rações (isoprotéicas) foi realizado duas vezes ao dia, às 6 e 14h, em forma de ração completa. A palma foi picada manualmente antes de ser misturada à silagem de sorgo e aos concentrados e, para garantir o consumo voluntário e manter os níveis dos diferentes tratamentos, foi fornecida em quantidade suficiente para permitir sobras de 5 a $10 \%$ do total oferecido, com base na MS.

Durante o período de coleta, diariamente, amostras da dieta e das sobras foram recolhidas, pré-secas em estufa de ventilação forçada a $60^{\circ} \mathrm{C}$, identificadas e armazenadas em sacos de papel, para formarem, ao final de cada período experimental, amostras compostas por animal por período.

Foram coletadas amostras de fezes diretamente na ampola retal no $11^{\circ}$ e $17^{\circ}$ dias de cada período experimental, as quais foram secas em estufa de ventilação forçada a $60^{\circ} \mathrm{C}$ por 72 horas, moídas e acondicionadas em recipientes plásticos para posterior análise.

As amostras do alimento oferecido, das sobras e das fezes foram moídas, identificadas e acondicionadas em recipientes plásticos. Posteriormente, foram mantidas em estufa por 12 horas $\left(105^{\circ} \mathrm{C}\right)$, para determinação da MS de acordo com metodologia descrita pela AOAC (1980). Foram estimados os teores de MM, EE e PB, conforme descrito por Silva (1990); de FDN e FDA, segundo Van Soest et al. (1991); e de MO, pela diferença da MM pelo total de MS. Os CNF dos concentrados foram calculados, também por diferença, segundo Hall (1997), e os CHOT, pelo somatório das frações de FDN e CNF.

O consumo dos nutrientes foi estimado por meio da diferença entre o total do nutriente nos alimentos ofertados e o total contido nas sobras.

As digestibilidades de MS foram estimadas utilizando-se a FDAi (fibra em detergente ácido indigestível) como indi- cador interno, conforme recomendado por Berchielli et al. (2000). Amostras de alimento, sobras e fezes, para cada um dos níveis de substituição e períodos, foram incubadas por 144 horas no rúmen fistulado de um bovino macho adulto, segundo metodologia de Cochran et al. (1986), com adaptação do método de incubação in vitro. Os coeficientes de digestibilidade aparente da MS e dos demais nutrientes foram estimados segundo Coelho da Silva \& Leão (1979).

Os nutrientes digestíveis totais para mantença, os níveis de energia digestível para mantença $\left(\mathrm{ED}_{1 \mathrm{x}}\right)$ e produção $\left(\mathrm{ED}_{\mathrm{P}}\right)$ e as frações de energia metabolizável $\left(\mathrm{EM}_{\mathrm{P}}\right)$ e energia líquida $\left(\mathrm{EL}_{\mathrm{Lp}}\right)$ das dietas foram estimados de acordo com o NRC (2001).

As dietas, constituídas de silagem de sorgo, palma forrageira e concentrado, foram formuladas para atender às exigências de vacas com produção diária de $15 \mathrm{~kg}$ de leite, de acordo com o NRC (1989). Foram testados quatro níveis de substituição do farelo de soja $(0,33,67$ e 100\%, com base na MS) por raspa de mandioca+uréia no concentrado das dietas (Tabela 1). A raspa de mandioca foi obtida a partir da raiz desintegrada (casca e polpa), seca ao sol e moída, antes de ser incorporada às rações.

A mistura uréia+sulfato de amônio foi elaborada na proporção de nove partes de uréia para uma de sulfato de amônio, com o objetivo de fornecer enxofre para a síntese de aminoácidos sulfurados (metionina, cistina e cisteína) pela microbiota ruminal, segundo Santos et al. (2001).

A composição química da silagem de sorgo, da palma forrageira, dos concentrados e das dietas experimentais encontra-se na Tabela 2.

Foram realizadas duas ordenhas diárias (às 5 e 14h), efetuando-se o registro da produção por animal e a coleta de amostras de leite no segundo e último dia de cada período

Tabela 1 - Composição das dietas experimentais (\% da MS) Table 1 - Ingredient composition of the experimental diets (\% of DM)

\begin{tabular}{|c|c|c|c|c|}
\hline \multirow[t]{2}{*}{$\begin{array}{l}\text { Ingrediente } \\
\text { Ingredient }\end{array}$} & \multicolumn{4}{|c|}{$\begin{array}{c}\text { Nível de substituição (\%) } \\
\text { Replacement level (\%) }\end{array}$} \\
\hline & 0 & 33 & 67 & 100 \\
\hline $\begin{array}{l}\text { Silagem de sorgo } \\
\text { Sorghum silage }\end{array}$ & 38,34 & 38,35 & 38,50 & 38,53 \\
\hline $\begin{array}{l}\text { Palma forrageira } \\
\text { Forage cactus }\end{array}$ & 43,87 & 43,94 & 44,14 & 44,08 \\
\hline $\begin{array}{l}\text { Farelo de soja } \\
\text { Soybean meal }\end{array}$ & 16,39 & 10,90 & 5,38 & 0,00 \\
\hline $\begin{array}{l}\text { Raspa de mandioca } \\
\text { Cassava scrapings }\end{array}$ & 0,00 & 4,42 & 8,65 & 13,07 \\
\hline $\begin{array}{l}\text { Uréia }+ \text { sulfato de amônio } \\
\text { Urea }+ \text { ammonium sulphate }\end{array}$ & 0,00 & 0,99 & 1,93 & 2,92 \\
\hline $\begin{array}{l}\text { Mistura mineral } \\
\text { Mineral mix }\end{array}$ & 1,40 & 1,40 & 1,40 & 1,40 \\
\hline
\end{tabular}


Tabela 2 - Teores de nutrientes da silagem de sorgo, da palma forrageira, dos concentrados (C1, C2, C3 e C4) e das dietas experimentais Table 2 Chemical composition of sorghum silage (SS), cactus forage (CF), concentrates (C1, C2, C3 e C4), and experimental diets

\begin{tabular}{|c|c|c|c|c|c|c|c|c|c|c|}
\hline \multirow[t]{2}{*}{$\begin{array}{l}\text { Nutriente } \\
\text { Nutrient }\end{array}$} & \multicolumn{6}{|c|}{$\begin{array}{l}\text { Ingrediente } \\
\text { Ingredient }\end{array}$} & \multicolumn{4}{|c|}{$\begin{array}{l}\text { Nível de substituição (\%) } \\
\text { Replacement level (\%) }\end{array}$} \\
\hline & Silagem (SS) & Palma $(C F)$ & $\mathrm{C} 1$ & $\mathrm{C} 2$ & $\mathrm{C} 3$ & $\mathrm{C} 4$ & 0 & 33 & 67 & 100 \\
\hline MO $(O M)^{1}$ & 92,18 & 83,06 & 88,65 & 89,56 & 90,07 & 91,52 & 87,55 & 87,71 & 87,79 & 88,05 \\
\hline $\mathrm{PB}(C P)^{1}$ & 5,79 & 5,89 & 48,87 & 49,80 & 48,07 & 49,87 & 13,50 & 13,62 & 13,16 & 13,49 \\
\hline $\mathrm{EE}^{1}$ & 2,86 & 2,60 & 1,85 & 1,31 & 0,87 & 0,78 & 2,57 & 2,47 & 2,40 & 2,38 \\
\hline FDN $(N D F)^{1}$ & 72,81 & 38,48 & 15,91 & 11,18 & 8,20 & 4,84 & 42,68 & 41,79 & 41,18 & 40,73 \\
\hline FDA $(A D F)^{1}$ & 36,91 & 15,29 & 10,86 & 8,29 & 5,37 & 2,58 & 25,84 & 25,01 & 24,55 & 23,97 \\
\hline PIDA $(A D I P)^{1}$ & 1,50 & 1,42 & 3,32 & 2,41 & 1,29 & 0,20 & - & - & - & - \\
\hline PIDN $(N D I P)^{1}$ & 1,55 & 0,95 & 3,98 & 2,46 & 0,74 & 0,43 & - & - & - & - \\
\hline $\mathrm{NDT}_{1 \mathrm{x}}\left(T D N_{1 X}\right)(\%)$ & 53,20 & 62,28 & 76,81 & 77,45 & 78,65 & 81,27 & 61,38 & 61,48 & 61,62 & 62,07 \\
\hline $\mathrm{EL}_{\mathrm{Lp}}\left(N E_{L p}\right)(\mathrm{Mcal} / \mathrm{kg})$ & - & - & - & - & - & - & 1,32 & 1,31 & 1,29 & 1,29 \\
\hline
\end{tabular}

${ }^{1}$ Porcentagem da matéria seca (dry matter percentage); PIDA - proteína insolúvel em detergente ácido; PIDN - proteína insolúvel em detergente neutro; $\mathrm{NDT}_{1 \mathrm{x}}$ - nutrientes digestíveis totais no nível de mantença; $\mathrm{EL}_{\mathrm{Lp}}$ - energia líquida de produção ao nível de ingestão (ADIP - acid detergent insoluble protein; $N D I P$-neutral detergent insoluble protein; $T D N_{1 X}$-total digestible nutrient at one times maintenance; $N E_{L p}$-net energy at production levels of intake).

experimental, para determinação do teor de gordura, utilizando-se o método de Gerber, descrito por Behmer (1965).

Efetuaram-se o cálculo da produção de leite corrigida para $4,0 \%$ de gordura ( $\mathrm{PLC}_{4,0} \%$, segundo o NRC (2001), e as estimativas das exigências de energia líquida para mantença e produção dos animais, expressas em Mcal/dia, para a realização do balanço de energia líquida.

As eficiências alimentares nos tratamentos foram calculadas considerando-se a razão entre a produção de leite corrigida para $4 \%$ de gordura e a MS consumida. Os dados foram submetidos às análises de variância e regressão, utilizando-se o sistema de análises estatísticas e genéticas, SAEG(UFV, 1998).

\section{Resultados e Discussão}

Os resultados referentes aos consumos de MS e dos demais nutrientes, em quilogramas por dia, aos consumos de MS e FDN, em porcentagem do peso vivo (\%PV), e ao consumo de MS, em gramas por unidade de peso metabólico $\left(\mathrm{g} / \mathrm{kg} \mathrm{PV}^{0,75}\right)$, são apresentados na Tabela 3 .

Foram encontradas reduções lineares $(\mathrm{P}<005)$ nas ingestões de matéria seca (IMS), nas três formas de expressão, com o aumento da inclusão da raspa de mandioca+uréia em substituição ao farelo de soja (Tabela 3). A equação de regressão indicou decréscimo de $15 \mathrm{~g}(0,1 \%)$ na IMS a cada unidade percentual de substituição do farelo de soja pela raspa de mandioca+uréia.

Comportamento semelhante foi registrado por Oliveira et al. (2001), em estudo com quatro níveis de compostos nitrogenados não-protéicos $(0 ; 0,7 ; 1,4$ e 2,1\% de uréia na MS) em rações para vacas Holandesas lactantes com produção média de $20 \mathrm{~kg}$ de leite/dia. Silva et al. (2001) e Melo et al. (2003b) também constataram diminuição nas IMS com o aumento dos níveis de NNP em vacas mestiças lactantes alimentadas com quatro níveis de uréia $(0 ; 0,7$; 1,4 e 2,1\% na MS). Melo et al. (2003b), no entanto, substituíram $0,18,36$ e $54 \%$ do farelo de soja por uréia+palma forrageira, correspondendo a $0 ; 0,8 ; 1,6 ;$ e $2,4 \%$ de uréia na MS das rações.

Uma possível explicação para essa diminuição linear nas IMS com o aumento nos níveis de raspa de mandioca+uréia das dietas parece estar relacionada a fatores psicogênicos, pois as dietas possuíam níveis próximos de FDN e NDT ${ }_{1 \mathrm{x}}$. Além disso, durante a limpeza dos cochos e a coleta das sobras, verificou-se odor característico de resíduos de uréia.

Os fatores primários que controlam a ingestão são respostas aos efeitos diretos da dieta, como distensão da parede ruminal, $\mathrm{pH}$ do conteúdo do rúmen, concentração de acetato e taxa hepática de propionato, assim como os fatores metabólicos mediados pelo sistema nervoso central, que incluem o tamanho da massa adiposa e a exigência nutricional, como a de energia, para satisfazer a mantença e produção (NRC, 1987). Segundo Mertens (1994), esses mecanismos podem agir isoladamente ou em conjunto. A regulação fisiológica ocorre quando a ingestão é proporcional à demanda energética para a produção, ou seja, quando a quantidade de energia consumida na dieta supre a necessidade do animal. A limitação física ocorre quando os animais são alimentados com dietas palatáveis, ricas em fibra e com baixa concentração de energia, sendo a ingestão limitada por uma restrição da capacidade do trato digestivo ou da capacidade de distensão ruminal. Em dietas de baixa 
Tabela 3 - Consumo de MS e nutrientes, coeficientes de variação (CV), equações de regressão, probabilidade (P) e coeficiente de determinação $\left(r^{2}\right)$, de acordo com as dietas experimentais

Table 3 - Average intakes of DM and nutrients, coefficients of variation (CV), fitted regression equations, level of probability ( $P$ ), and the respective coefficients of determination $\left(r^{2}\right)$ in function of the experimental diets

\begin{tabular}{|c|c|c|c|c|c|c|c|c|}
\hline \multirow[t]{2}{*}{$\begin{array}{l}\text { Consumo } \\
\text { Intake }\end{array}$} & \multicolumn{4}{|c|}{$\begin{array}{c}\text { Nível de substituição (\%) } \\
\text { Replacement level (\%) }\end{array}$} & \multirow[t]{2}{*}{$\mathrm{CV}(\%)$} & \multirow[t]{2}{*}{$\begin{array}{l}\text { Regressão } \\
\text { Regression }\end{array}$} & \multirow[t]{2}{*}{$\mathrm{P}$} & \multirow[t]{2}{*}{$\mathrm{r}^{2}$} \\
\hline & 0 & 33 & 67 & 100 & & & & \\
\hline MS (\% PV) (DM, BW\%) & 3,34 & 3,24 & 3,25 & 3,07 & 7,61 & $\hat{\mathrm{Y}}=3,34-0,002 \mathrm{NS}$ & 0,049 & 0,82 \\
\hline $\operatorname{MS}\left(\mathrm{g} / \mathrm{kg} \mathrm{PV} V^{0,75}\right)\left(D M, g / B W k^{0.75}\right)$ & 158,96 & 154,39 & 154,69 & 145,46 & 7,36 & $\hat{\mathrm{Y}}=159,38-0,120 \mathrm{NS}$ & 0,048 & 0,84 \\
\hline MO $(O M)^{1}$ & 15,06 & 14,70 & 14,62 & 13,64 & 6,97 & $\hat{\mathrm{Y}}=15,16-0,013 \mathrm{NS}$ & 0,021 & 0,85 \\
\hline CHOT $(\text { TCHO })^{1}$ & 12,19 & 11,91 & 12,01 & 11,16 & 7,44 & $\hat{\mathrm{Y}}=12,27-0,009 \mathrm{NS}$ & 0,042 & 0,73 \\
\hline $\mathrm{CNF}(N F C)^{1}$ & 5,00 & 5,09 & 5,17 & 4,58 & 11,43 & $\hat{\mathrm{Y}}=5,14-0,004 \mathrm{NS}$ & 0,252 & 0,69 \\
\hline $\mathrm{FDN}(N D F)^{1}$ & 7,19 & 6,83 & 6,84 & 6,58 & 7,18 & $\hat{\mathrm{Y}}=7,13-0,005 \mathrm{NS}$ & 0,043 & 0,88 \\
\hline FDN (\% PV) (NDF, BW\%) & 1,39 & 1,32 & 1,33 & 1,29 & 8,00 & $\hat{\mathrm{Y}}=1,37-0,0008 \mathrm{NS}$ & 0,118 & 0,76 \\
\hline FDA $(A D F)^{1}$ & 4,34 & 4,05 & 4,06 & 3,80 & 15,99 & $\hat{\mathrm{Y}}=4,30-0,005 \mathrm{NS}$ & 0,138 & 0,61 \\
\hline $\mathrm{NDT}(T D N)^{1}$ & 10,59 & 10,33 & 10,30 & 9,67 & 12,94 & $\hat{\mathrm{Y}}=11,23-0,008 \mathrm{NS}$ & 0,242 & 0,62 \\
\hline
\end{tabular}

${ }^{1} \mathrm{~kg} ;{ }^{*} \mathrm{NS}$ - nível de substituição (NS - level of replacement).

digestibilidade, o consumo de alimentos eleva-se com o aumento do valor nutritivo até que a distensão ruminal não permita maior ingestão, inibindo o consumo de MS antes que esteja satisfeita a demanda total de energia do animal. A regulação por fatores psicogênicos é afetada por mecanismos inibidores ou estimuladores relacionados ao alimento ou ao ambiente que não são considerados pelo modelo da energia ou do enchimento do rúmen (odor, sabor, textura, cor, entre outros), o que, talvez, possa explicar a diminuição linear nas IMS. Além disso, níveis elevados de NNP nas dietas poderiam induzir à toxidez, pelo excesso de liberação de amônia, causando redução do consumo, embora, durante o experimento, não tenham sido observadas alterações no comportamento dos animais que indicassem sinais de intoxicação alimentar.

Outra possível explicação seria a de que dietas ricas em CNF e pectina, com elevados teores de umidade, poderiam causar aumento da viscosidade do líquido ruminal, formando uma espuma que diminuiria a absorção dos gases resultantes da fermentação. Sabe-se que grãos moídos finamente podem promover a formação dessa espuma estável e que a palma forrageira é rica em pectina, podendo gerar esse quadro, reduzindo o consumo. Entretanto, Ramalho (2005) substituiu $0,25,50,75$ e $100 \%$ do milho moído por raspa de mandioca em dietas à base de palma forrageira (médias de 45,64 e $19,8 \%$, para CNF e MS, respectivamente), fornecidas a vacas Holandesas lactantes com produção média de $23,6 \mathrm{~kg}$ de leite/dia), e não encontraram alterações nas IMS (média de 17,34), o que aparentemente reforça a teoria de menor palatabilidade das dietas com maior teor de uréia.

Torres et al. (2003) testaram a substituição parcial do farelo de soja por milho moído+uréia $(0,20,40$ e $60 \%)$ em dietas à base de palma forrageira para novilhas mestiças em crescimento. Esses autores utilizaram 0;0,6;1,2 e 1,8\% de uréia, com base na MS, e não encontraram diferença significativa sobre as IMS. Todavia, os consumos de MS e, conseqüentemente, os de uréia nos níveis de maior substituição do farelo de soja foram bem inferiores $(60 \mathrm{~g} / 100 \mathrm{~kg}$ de PV) aos deste estudo (109 g/100 kg de PV).

O consumo diário de MS observado durante o experimento foi, em média, $11,18 \%$ maior $(16,59 \mathrm{~kg})$ que o preconizado pelo NRC (2001), de 14,84 kg, quando considerados a produção de leite corrigida para $4 \%$ de gordura, o peso metabólico $\left(\mathrm{PV}^{0,75}\right)$ e o ajuste da ingestão pelo número de semanas em lactação. Ressalta-se que o percentual médio de MS das dietas experimentais foi de 14,39\% e que redução no consumo de alimentos seria esperada com o aumento dos níveis de umidade nas dietas (NRC, 2001). A influência do teor de umidade das dietas nas IMS explica-se pelo tempo total diário de mastigação dos alimentos, que não é alterado pelo teor de umidade das dietas, mas pelos menores teores de MS nas dietas (Lahr et al., 1983).

O nível de potássio $(\mathrm{K})$ das dietas pode ter sido a causa para IMS acima dos valores preconizados pelo NRC, pois a palma forrageira possui valores próximos a $2,4 \%$, com base na MS (Wanderley et al., 2002), possibilitando teores próximos a 2,0\%, valores que corroboram os citados por Sanchez et al. (1994), para o aumento nas ingestões de MS. Esses mesmos autores explicaram que, sob condições de estresse térmico, as vacas perdem mais K por sudorese, ocorrendo quebra da homeostase, e que níveis dietéticos acima do recomendado pelo NRC (2001), de 1,5\% com base na MS, interferem na IMS, com aumento linear até o limite de $2,0 \%$. 
Os consumos médios de MO, PB, EE, CHOT e FDN, em $\mathrm{kg} /$ dia, decresceram linearmente $(\mathrm{P}<0,05)$ com a inclusão crescente da mistura mandioca+uréia em substituição ao farelo de soja. A redução no consumo desses nutrientes provavelmente está associada ao consumo também decrescente de MS, visto que a composição nutricional das dietas experimentais foi semelhante.

O percentual de proteína nas dietas variou entre 13,16 e 13,62\% (Tabela 2). Esses valores satisfazem às exigências (entre 11,9 e 12,3\% de PB) preconizadas pelo NRC (2001) para animais com $500 \mathrm{~kg}$ de $\mathrm{PV}$, consumo de 15,58 a 17,26 kg de MS, produção de 13,55 a 16,59 kg de leite e percentual de gordura do leite de 3,68 a 3,86\%.

As dietas apresentaram, em média, $41,6 \%$ de FDN, o que está dentro dos limites recomendados pelo NRC (2001). Não houve influência dos níveis de substituição do farelo de soja sobre o consumo desse nutriente, expresso em porcentagem do peso vivo $(\% \mathrm{PV})$, com média de $1,33 \%$, próxima à recomendada por Mertens (2001), de 1,1 a 1,3\% do PV.

Verificou-se efeito quadrático nos coeficientes de digestibilidade dos nutrientes com a substituição do farelo de soja pela raspa de mandioca+uréia (Tabela 4). As equações de regressão apresentaram as maiores digestibilidades aparentes nos níveis de 51,54; 52,24; 53,54; 47,13; 52,52; 52,$08 ; 52,16$ e 49,95\% de substituição do farelo de soja, respectivamente,para as digestibilidades aparentes da MS, $\mathrm{MO}, \mathrm{PB}, \mathrm{EE}, \mathrm{CHOT}, \mathrm{CNF}$, FDN e FDA.

Oliveira et al. (2001) e Silva et al. (2001), em estudos com vacas puras Holandesas e mestiças Holandês: Gir, respectivamente, não encontraram diferenças nos coeficientes de digestibilidade aparente da MS ou dos demais nutrientes com a substituição do farelo de soja por milho moído+uréia.

A digestibilidade da dieta depende de vários fatores inter-relacionados, entre eles, as taxas de passagem e de digestão e o efeito associativo entre os ingredientes da dieta (Van Soest, 1994). Tyrrell \& Moe (1975) afirmaram que a digestibilidade da dieta consumida diminui com o aumento da IMS, sendo a magnitude dessa diminuição correlacionada ao percentual de grãos incluídos na dieta. Assim, aumentos nas IMS podem provocar aumentos na taxa de passagem do alimento pelo trato gastrintestinal, acarretando menor tempo de permanência dos nutrientes, diminuindo a eficiência com que esses nutrientes são absorvidos (NRC, 2001).

De acordo com o NRC (1985), a digestão ruminal é maximizada em um ecossistema equilibrado quanto ao $\mathrm{pH}$, à disponibilidade de nutrientes e ao aproveitamento dos produtos da fermentação pelas diversas micro-colônias de organismos que habitam o rúmen. Os resultados encontrados neste estudo parecem sugerir que o aumento nos níveis de CNF e NNP das dietas, como conseqüência da substituição do farelo de soja pela raspa de mandioca+uréia (Tabela 2), melhorou as condições ruminais para o desenvolvimento dos microrganismos e, com isso, aumentou os coeficientes de digestibilidade dos demais nutrientes, mas essa melhor condição pode ter sido alterada com níveis mais elevados de uréia, que podem ter acarretado alterações de $\mathrm{pH}$, excesso de amônia livre, ou ainda, deficiência de aminoácidos dietéticos para o crescimento de algumas espécies de microrganismos que não utilizam amônia para produzir seus próprios aminoácidos, justificando o efeito quadrático para esse parâmetro.

Os coeficientes de digestibilidade aparente da MS, MO, PB, EE, CHOT, CNF, FDN e FDA encontrados (Tabela 4) foram superiores aos observados por Oliveira et al. (2001) e Melo et al. (2003a), porém, semelhantes aos encontrados por Silva et al. (2001). A explicação para essas diferenças pode estar relacionada ao nível de ingestão dos animais em relação à mantença e/ou à proporção de alimentos concentrados nas dietas.

As produções de leite, de leite corrigido para $4 \%$ de gordura e de gordura do leite diminuíram linearmente

Tabela 4 - Digestibilidade aparente (DA) dos nutrientes, de acordo com as dietas experimentais

Table 4 - Apparent digestibility (AD) of nutrients in function of the experimental diets

\begin{tabular}{|c|c|c|c|c|c|c|c|c|c|}
\hline \multirow[t]{2}{*}{$\begin{array}{l}\mathrm{DA} \\
A D\end{array}$} & \multicolumn{4}{|c|}{$\begin{array}{c}\text { Nível de substituição (\%) } \\
\text { Replacement level (\%) }\end{array}$} & \multirow[t]{2}{*}{ CV $(\%)$} & \multirow{2}{*}{\multicolumn{2}{|c|}{$\begin{array}{l}\text { Regressão } \\
\text { Regression }\end{array}$}} & \multirow[t]{2}{*}{$\mathrm{P}$} & \multirow[t]{2}{*}{$\mathrm{r}^{2}$} \\
\hline & 0 & 33 & 67 & 100 & & & & & \\
\hline MO (OM) & 77,66 & 83,14 & 81,95 & 80,34 & 6,12 & $\hat{\mathrm{Y}}=78,4495$ & $+0,2403 \mathrm{NS}-0,0023 \mathrm{NS}^{2}$ & $<0,01$ & 0,69 \\
\hline $\mathrm{PB}(C P)$ & 78,37 & 84,79 & 83,52 & 81,61 & 7,18 & $\hat{Y}=79,1489$ & $+0,2677 \mathrm{NS}-0,0025 \mathrm{NS}^{2}$ & $<0,01$ & 0,73 \\
\hline $\mathrm{EE}$ & 83,38 & 86,02 & 85,26 & 83,85 & 4,75 & $\hat{\mathrm{Y}}=83,8985$ & $+0,1414 \mathrm{NS}-0,0015 \mathrm{NS}^{2}$ & 0,02 & 0,68 \\
\hline FDN $(N D F)$ & 68,19 & 73,36 & 73,24 & 71,61 & 11,42 & $\hat{Y}=69,2269$ & $+0,2921 \mathrm{NS}-0,0028 \mathrm{NS}^{2}$ & 0,02 & 0,65 \\
\hline FDA $(A D F)$ & 69,50 & 78,17 & 77,03 & 71,11 & 10,18 & $\hat{\mathrm{Y}}=70,2919$ & $+0,4096 \mathrm{NS}-0,0041 \mathrm{NS}^{2}$ & $<0,01$ & 0,87 \\
\hline
\end{tabular}

$\mathrm{R}^{2}$ - coeficiente de determinação (coefficient of determination); *NS nível de substituição (NS - level of replacement). 
$(\mathrm{P}<0,05)$ com a elevação dos níveis de substituição do farelo de soja pela raspa de mandioca+uréia nas dietas experimentais (Tabela 5).

Oliveira et al. (2001) trabalharam com 16 vacas lactantes (média de 18,87 kg de leite por dia) alimentadas com rações contendo, $0 ; 0,7 ; 1,4$ e 2,1\% de uréia na MS, utilizando rações que continham aproximadamente $14 \%$ de $\mathrm{PB}$ e $60 \%$ de silagem de milho na MS. Esses autores encontraram redução linear de $2,1 \%$ nas produções de leite, corrigidas ou não para 3,5\% de gordura, com o aumento de cada unidade no teor de NNP das rações. Comportamento semelhante foi verificado em outros dois trabalhos de substituição do farelo de soja por uma fonte de energia+uréia (Silva et al., 2001; Melo et al., 2003b).

A redução na produção de leite pode estar relacionada à diminuição nas ingestões de MS com a substituição do farelo de soja pela raspa de mandioca+uréia, acarretando menores ingestões de nutrientes, e aos percentuais de proteína não-degradável (PNDR) contidos nas dietas. $\mathrm{O}$ NRC (1985) afirma que a exigência em PNDR cresce com o aumento na produção de leite e/ou com o percentual de PB da dieta, porém, sofre influência da IMS e da concentração energética da dieta. Esse conselho destaca que vacas com produção em torno de $10 \mathrm{~kg}$ de leite/dia apresentam exigência próxima a 30\% da PB dietética em PNDR. Com a substituição do farelo de soja, que possui em média $30 \%$ de PNDR em relação ao total de $\mathrm{PB}$, pela uréia, que não possui PNDR, pode ter ocorrido diminuição dos percentuais de PNDR das dietas, o que, provavelmente, ocasionou a redução da produção de leite. Segundo o NRC (2001), limitações de PNDR são acompanhadas de limitações em aminoácidos essenciais, principalmente metionina e lisina, na proteína metabolizável, o que poderia promover a diminuição da produção de leite. Santos et al. (2001) relatam que, quando ocorre excesso de PDR, há um dispêndio em energia para converter a amônia do fígado em uréia, com perda do nitrogênio que deveria ser convertido em proteína microbiana para ser digerida no intestino delgado. Estas afirmativas podem explicar a queda linear na produção de leite com o aumento dos níveis de raspa de mandioca+uréia na dieta. Entretanto, Cruz (2002) estudou as concentrações de uréia plasmática no leite e na urina e a excreção de nitrogênio nas fezes e não encontrou diferenças significativas que comprovassem o desbalanço entre PDR e PNDR.

Os teores de gordura no leite, em porcentagem, não foram influenciados $(\mathrm{P}>0,05)$ pelos tratamentos (Tabela 5), o que está de acordo com os resultados descritos na literatura (Oliveira et al. 2001; Melo et al. 2003b). Silva et al. (2001) encontraram diminuição linear no percentual de gordura do leite ao elevarem os níveis de nitrogênio nãoprotéico das dietas experimentais e atribuíram esse efeito às menores ingestões de MS observadas.

Os balanços de energia líquida (BEL) foram positivos com relação às exigências de mantença e produção; isto é, houve sobra de energia para outras funções além da produção de leite em todos os níveis de substituição testados $(2,28 ; 2,24 ; 2,06$ e $1,55 \mathrm{Mcal} /$ dia, respectivamente, para os níveis $0 ; 33 ; 67$ e 100\% de substituição do farelo de soja) e, possivelmente, esse desvio de energia líquida esteja relacionado às variações positivas nos pesos dos animais durante o experimento.

A eficiência alimentar (em kg de leite corrigido para 4\% de gordura em relação à IMS) não foi influenciada $(\mathrm{P}>0,05)$ pela substituição do farelo de soja pela raspa de mandioca+uréia, apresentando valor médio de 0,88 ; mas apresentou tendência de diminuição. Esse valor médio foi inferior aos encontrados por Matos et al. (2000), Dias et al. (2001) e Melo et al. (2003b) e superior aos obtidos por Magalhães et al. (2002). Os resultados para a eficiência alimentar refletem a inviabilidade de substituição do farelo de soja quando seu custo de aquisição for próximo ao da raspa de mandioca+uréia. Para se inferir sobre esses resultados, torna-se necessária a análise econômica, ponderando-se os custos com aquisição e processamento da raspa de mandioca+uréia em comparação aos do farelo de soja.

Tabela 5 - Produção de leite (PL), produção de leite corrigida para gordura (PLC), teor de gordura do leite (\%G) e eficiência alimentar (EA), de acordo com as dietas experimentais

Table 5 - $\quad$ Milk yield (MY), fat corrected milk (FCM), fat percentage (Fat), fat yield (FatY), and feed efficiency (FE) in function of the experimental diets

\begin{tabular}{|c|c|c|c|c|c|c|c|c|}
\hline \multirow[t]{2}{*}{$\begin{array}{l}\text { Parâmetro } \\
\text { Parameter }\end{array}$} & \multicolumn{4}{|c|}{$\begin{array}{l}\text { Nível de substituição (\%) } \\
\text { Replacement level (\%) }\end{array}$} & \multirow[t]{2}{*}{$\mathrm{CV}(\%)$} & \multirow[t]{2}{*}{$\begin{array}{l}\text { Regressão } \\
\text { Regression }\end{array}$} & \multirow[t]{2}{*}{$\mathrm{P}$} & \multirow[t]{2}{*}{$r^{2}$} \\
\hline & 0 & 33 & 67 & 100 & & & & \\
\hline PLC $(\mathrm{kg})(F C M, k g)$ & 15,76 & 14,84 & 14,59 & 13,27 & 4,96 & $\hat{\mathrm{Y}}=15,77-0,02 \mathrm{NS}$ & $<0,01$ & 0,94 \\
\hline$\% \mathrm{G}($ Fat,$\%)$ & 3,68 & 3,73 & 3,87 & 3,86 & 5,43 & $\hat{\mathrm{Y}}=3,68+0,002 \mathrm{NS}$ & 0,148 & 0,95 \\
\hline PG $(\mathrm{g})($ Fat $Y, g)$ & 608,02 & 576,99 & 576,72 & 523,24 & 6,52 & $\hat{\mathrm{Y}}=610-0,8 \mathrm{NS}$ & $<0,01$ & 0,87 \\
\hline
\end{tabular}

$\mathrm{r}^{2}$ - coeficiente de determinação (coefficient of determination); *NS nível de substituição (NS - level of replacement). 


\section{Conclusões}

A mistura raspa de mandioca+uréia não substitui o farelo de soja em dietas à base de palma forrageira para vacas mestiças em lactação. Apesar de não interferir no teor de gordura do leite, essa substituição influencia negativamente o consumo e o desempenho animal, afetando de forma quadrática a digestibilidade dos nutrientes.

\section{Literatura Citada}

ASSOCIATION OF OFFICIAL ANALYTICAL CHEMISTS - AOAC. Official methods of analisys. 13.ed. Washington, D.C.: 1980. $1018 \mathrm{p}$.

BEHMER, M.L.A. Laticínios, leite, manteiga, queijo, caseína e instalações. 3.ed. São Paulo: Melhoramentos, 1965. 294p.

BERCHIELLI, T.T.; ANDRADE, P.; FURLAN, C.L. Avaliação de indicadores internos em ensaios de digestibilidade. Revista Brasileira de Zootecnia, v.29, n.3, p.830-833, 2000.

COCHRAN, R.C.; ADAMS, D.C.; WALLACE, J.D. et al. Predicting digestibility of different diets with internal markers: evaluation of four potential markers. Journal of Animal Science, v.63, n.5, p.1476-1483, 1986.

CHURCH, D.C. Gusto, apetito e regulacion de la ingesta de alimentos In: CHURCH, D.C. (Ed.) Fisiologia digestiva y nutricion de los ruminantes. Zaragoza: Acribia, 1974. v.2, p.405-435.

CRUZ, M.C.S. Estimativas de perdas endógenas e balanço de nitrogênio em vacas lactantes alimentadas com níveis crescentes de uréia e mandioca. Recife: Universidade Federal Rural de Pernambuco, 2002. 49p. Dissertação (Mestrado em Zootecnia) - Universidade Federal Rural de Pernambuco, 2002.

DIAS, A.M.A.; BATISTA, A.M.V.; FERREIRA, M.A. et al. Efeito do estádio vegetativo do sorgo (Sorghum bicolor, (L.) Moench) sobre a composição química da silagem, consumo, produção e teor de gordura do leite para vacas em lactação, em comparação à silagem de milho (Zea mays (L.)). Revista Brasileira de Zootecnia, v.30, n.6, sup1, p.2086-2092, 2001.

FREGADOLLI, F.L.; ZEOULA, L.M; PRADO, I.N. et al. Efeito das fontes de amido e nitrogênio de diferentes degradabilidades ruminais. 1. Digestibilidades parcial e total. Revista Brasileira de Zootecnia, v.30, n.3, p.858-869, 2001.

HALL, M.B. New equations may improve NSC estimating. Feedstuffs, v.69, n. 37, p.12-14, 1997

LAHR, D.A.; OTTERBY, D.E.; JOHNSON, D.G. et al. Effects of moisture content of complete diets on feed intake and milk production by cows. Journal of Dairy Science, v.66, n.6, p.1891-1900, 1983.

LINES, L.W.; WEISS, W.P. Use of nitrogen from ammoniated alfalfa hay, urea, soybean meal, and animal protein meal by lactating cows. Journal of Dairy Science, v.79, n.11, p.1992-1999, 1996.

MAGALHÃES, M.C.S.; VÉRAS, A.S.C.; FERREIRA, M.A. et al. Cama de frango associada à palma forrageira (Opuntia fícus ndica Mill), na alimentação de vacas mestiças. II. Produção de leite. In: REUNIÃO ANUAL DA SOCIEDADE BRASILEIRA DE ZOOTECNIA, 39., 2002, Recife. Anais... Pernambuco, 2002 (CD-ROM). Nutrição de Ruminantes. 06sbz1218.pdf.

MATOS, L.M.E.; FERREIRA, M.A.; SANTOS, D.C. et al. Associação da palma forrageira (Opuntia ficus indica Mill) com diferentes fontes de fibra na alimentação de vacas $5 / 8$ HolandêsZebu em lactação. Revista Brasileira de Zootecnia, v.29, n.6, p.2128-2134, 2000.

MELO, A.A.S.; FERREIRA, M.A.; VÉRAS, A.S.C. et al. Substituição parcial do farelo de soja por uréia e palma forrageira (Opuntia ficus indica Mill cv Gigante) em dietas para vacas em lactação.
Digestibilidade. Acta Scientiarum.Animal Sciences, v.25, n.2, p.339-345, 2003a.

MELO, A.A.S.; FERREIRA, M.A.; VÉRAS, A.S.C. et al. Substituição parcial do farelo de soja por uréia e palma forrageira (Opuntia ficus indica Mill) em dietas para vacas em lactação. 1. Desempenho. Revista Brasileira de Zootecnia, v.32, n.3, p.727-736, 2003b.

MERTENS, D.R. Regulation of forage intake. In: Forage quality evaluation and utilization. FAHEY, JR. (Ed.) American Society of Agronomy: Madison, 1994. p.450-493.

MERTENS, D.R. Physically effective NDF and its use in formulating dairy rations. In: SIMPÓSIO INTERNACIONAL EM BOVINOCULTURA DE LEITE: NOVOS CONCEITOS EM NUTRIÇÃO, 2., 2001, Lavras. Anais... Lavras: Universidade Federal de Lavras, 2001. p.25-36.

NATIONAL RESEARCH COUNCIL - NRC. Ruminant nitrogen usage. Washington: D.C.: National Academy of Science, 1985. $138 \mathrm{p}$.

NATIONAL RESEARCH COUNCIL - NRC. Predicting feed intake of food-producing animals. Washington: D.C.: National Academy of Science, 1987. 85p.

NATIONAL RESEARCH COUNCIL - NRC. Nutrient requirements of the dairy cattle. 6.ed. Washington: D.C.: National Academy of Science, 1989. 158p.

NATIONAL RESEARCH COUNCIL - NRC. Nutrient requirements of the dairy cattle. 7.ed. Washington: D.C.: National Academy of Science, 2001. 363p.

OLIVEIRA, A.S.; VALADARES, R.F.D.; VALADARES FILHO, S.C.; et al. Consumo, digestibilidade aparente, produção e composição do leite em vacas alimentadas com quatro níveis de compostos nitrogenados não-protéicos. Revista Brasileira de Zootecnia, v.30, n.4, p.1358-1366, 2001.

RAMALHO, R.P. Raspa de mandioca na alimentação de vacas leiteiras. Areia: Universidade Federal da Paraíba, 2005. 53p. Tese (Doutorado em Zootecnia) - Universidade Federal da Paraíba, 2005.

ROSELER, D.K.; FERGUNSON, J.D.; SNIFFEN, C.J. et al. Dietary protein degradability efeects on plasma and milk urea nitrogen and milk non-protein nitrogen in Holstein cows. Journal of Dairy Science, v.76, n.2, p.525-534, 1993.

RUSSELL, J.B.; COTTA, M.A; DOMBROWSKI, D.B. Rumen bacterial competition in continuous culture: "Streptococcus bovis" versus Megasphaera elsdenii. Applied and Environmental Microbiology, v.41, p.1394-1399, 1981.

SANCHEZ, W.K.; McGUIRE, M.A.; BEEDE, D.K. Macromineral nutrition by heat stress interactions in dairy cattle: review and original research. Journal of Dairy Science, v.77, p.2051- 2079, 1994.

SANTOS, T.G.; CAVALIERI, F.L.B.; MOdestO, E.C. Recentes avanços em nitrogênio não-protéico na nutrição de vacas leiteiras. In: SIMPÓSIO INTERNACIONAL EM BOVINOCULTURA DE LEITE: NOVOS CONCEITOS EM NUTRIÇÃO, 2., 2001, Lavras. Anais... Lavras: Universidade Federal de Lavras, 2001. p.199-228.

SILVA, J.F.C.; LEÃO, M.I. Fundamentos de nutrição dos ruminantes. Piracicaba: Livroceres, 1979. 380p.

SILVA, D.J. Análise de alimentos (métodos químicos e biológicos). Viçosa, MG: Universidade Federal de Viçosa, 1990. 165p.

SILVA, R.M.N.; VALADARES, R.F.D.; VALADARES FILHO, S.C.; et al. Uréia para vacas em lactação. 1. Consumo, digestibilidade, produção e composição do leite. Revista Brasileira de Zootecnia, v.30, n.5, p.1639-1649, 2001.

TORRES, L.B.; FERREIRA, M.A.; VÉRAS, A.S.C. et al. Níveis de bagaço de cana e uréia como substituto ao farelo de soja em dietas para bovinos leiteiros em crescimento. Revista Brasileira de Zootecnia, v.32, n.3, p.760-767, 2003.

TYRRELL, H.F.; MOE, P.W. Effect of intake on digestive efficiency. Journal of Dairy Science, v.58, n.8, p.11511163, 1975. 
UNIVERSIDADE FEDERAL DE VIÇOSA - UFV. SAEG - Sistema de análises estatísticas e genéticas. Versão 7.1.Viçosa, MG: 1998. 150p. (Manual do usuário).

Van SOEST, P.J.; ROBERTSON, J.B.; LEWIS, B.A. Methods for dietary fiber, neutral detergent fiber, and nonstarch polysaccarides in relation to animal nutrition. Journal of Dairy Science, v.74, n.10, p.3583-3597, 1991.

Van SOEST, P.J. Nutritional ecology of the ruminant. 2.ed. New York: Cornell University Press, 1994. 476p.
WANDERLEY, W.L.; FERREIRA, M.A.; ANDRADE, D.K.B. et al. Palma forrageira (Opuntia ficus indica Mill) em substituição à silagem de sorgo (Sorghum bicolor (L.) Moench) na alimentação de vacas leiteiras. Revista Brasileira de Zootecnia, v.31, n.1, p.272-281, 2002.

Recebido: 04/03/05 Aprovado:02/12/05 